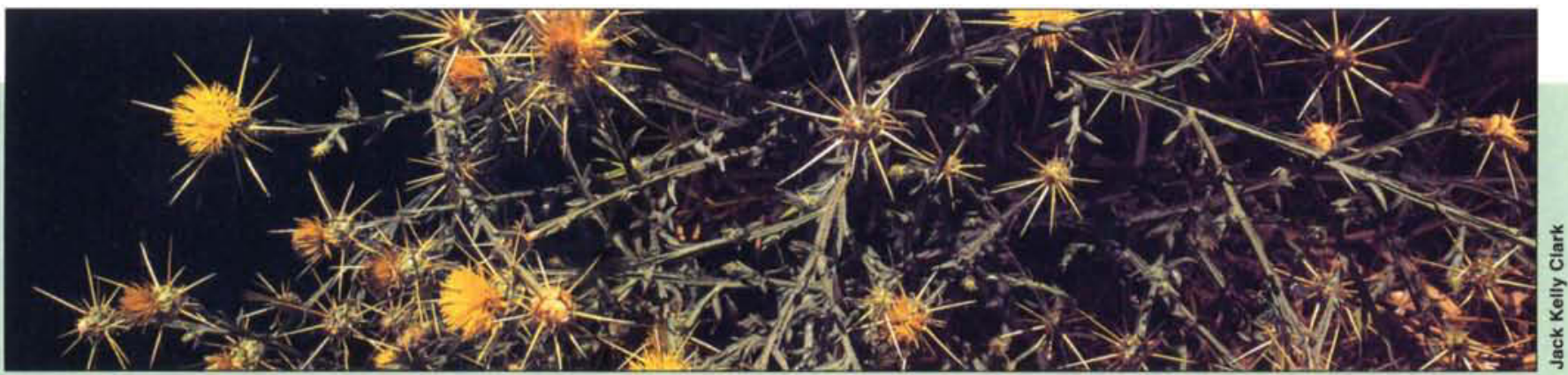

Habitat fragments are more susceptible to harmful outside influences including the invasion of exotic plant species such as this starthistle.

\title{
Habitat fragmentation: the sum of the pieces is less than the whole
}

Most of us envision two Californias: one where we live and work, and another where the wild things roam free. This distinction enables us to live and build as we please as if there were a vast realm of untapped potential just over the next hill. But while we conjure dreams of separate and distant wildlands, the reality is that our pattern of land development has rearranged wild California into mosaic of wildlife habitat and human uses. The pieces of this mosaic range from urban outposts surrounded by wildland to remnant patches of habitat embedded in suburbs. This fragmentation of habitat represents one of the biggest threats to the state's biodiversity, not only because it challenges the survival of many species, but because its slow pace and insidious effects usually escape our attention.

The ability of these fragmented habitats to maintain their plant and animals species depends on the size of remnant patches, the distance between patches, and the amount of edge they share with human land uses. The small size of many habitat fragments limits the types of species living there. For example, small fragments may not provide enough food for species such as golden eagles that require large areas, and may not support enough songbirds to maintain population viability. The loss of one species can alter the composition and numbers of other species.

\section{Tom Scott a Nanette Pratini}

Habitat fragmentation also creates barriers to species movement. Most California species have dispersal mechanisms that link populations across natural landscapes: entire populations may migrate by season (such as deer in the Sierra Nevada), juvenile animals often move away from their birth places, and seeds are dispersed by wind or birds. These biological processes represent gene flow, adaptations to seasonal environments, and ways of finding mates or new habitats. Populations that become isolated by habitat fragmentation are more susceptible to disasters and epidemics, and may die out locally when immigration is no longer possible.

Moreover, because fragmentation increases the amount of edge between human and wildlife habitats, fragments are more susceptible to harmful outside influences. These edge effects include invasions of exotic plant species, point and non-point source pollution, refuse dumping, noise, lights at night, killing by exotic predators, and unregulated recreational use of fragments. The smaller the fragment, the greater the effects of these outside disturbances. Smaller fragments tend to have lower numbers of sensitive species (those that decline with human disturbance) and fragments that are less than five acres are often too small for maintaining undisturbed habitats.

In many ways, the fragmentation of California's wildlands has become a multibillion-dollar manipulation of natural selection and species adjustments. (In the late 1980 s, the value of single-family detached housing construction exceeded $\$ 17$ billion annually). Although land conversion processes have little in common with natural events, each species will attempt to compensate for habitat alterations by changing its behavior. Some species, such as scrub jays or northern mockingbirds, exploit fragmented landscapes and increase their numbers. Other species, such as the longeared kit fox, have been unable to adjust to altered conditions and have gone extinct. Most species fall somewhere between the extremes. To increase the chances of their survival, we need to understand the mechanisms and the extent of species compensation for human actions. We are in a footrace with habitat fragmentation as we try to discover enough about species' natural history, genetics, and patterns of adaptation to keep California's wildlife from moving across the threshold of extinction.

T. Scott is Extension Natural Resource and Wildlife Specialist, N. Pratini is Staff Research Associate, Integrated Hardwood Range Management Program, Department of Environmental Science Policy and Management, UC Berkeley. Both are located at the UC Riverside campus. 